This is the author's version of a work that was published in the following source:

Ried, S.; Jochem, P.; Fichtner, W. (2015). Profitability of photovoltaic battery systems considering temporal resolution ${ }_{\bullet}$.

2015 12th International Conference on the European Energy Market (EEM), Lisbon, Portugal, 19-22 May 2015, 1-5, IEEE. doi:10.1109/EEM.2015.7216632

Please note: Copyright is owned by the author(s) and / or the publisher. The commercial use of this copy is not allowed. 


\section{Profitability of Photovoltaic Battery Systems Considering Temporal Resolution}

\author{
Sabrina Ried \\ Chair of Energy Economics and Project Competence E \\ Karlsruhe Institute of Technology \\ Karlsruhe, Germany \\ sabrina.ried@kit.edu
}

\author{
Patrick Jochem and Wolf Fichtner \\ Chair of Energy Economics and KSRI \\ Karlsruhe Institute of Technology \\ Karlsruhe, Germany
}

\begin{abstract}
The rollout of residential photovoltaic (PV) battery systems is mainly motivated by cost saving. Investment decisions are often based on general figures such as the yearly electricity consumption. Simulations used for scientific publications often use standard load profiles or measured load profiles of a specific household. In the latter case, the decision of adequate temporal resolution has to be made. Our study analyzes the impact of temporal resolution on the expected profitability that is calculated based on simulations. In order to quantify this effect and its uncertainty, we conduct a study based on measured load profiles of 30 households.
\end{abstract}

Index Terms-- Power System Economics

\section{INTRODUCTION}

Decreasing prices of PV systems and a continuous reduction of feed in tariffs stimulate the own-consumption of electricity generated by PV systems in Germany. Furthermore, since 2013 the German Reconstruction Credit Institute KfW promotes new PV installations to be used primarily for ownconsumption by providing loans and repayment subsidies for batteries that are connected to the PV systems [1]. By the end of 2014, 1.5 million battery systems have been installed in Germany [2]. The profitability of PV battery systems is highly sensitive to electricity and battery prices, battery lifetime as well as the specific household load profile. The numerous studies of the profitability of residential PV battery systems often rely on measured load profiles of 15-minute time steps $[3,4,5]$, or on standard load profiles (SLP) of 1 minute to 1 hour temporal resolution $[6,7,8]$. Real load profiles of higher resolution are often not collected, since they require specific power measurement equipment, which is usually not installed in households. Some studies have analyzed the error in the matching of PV production and household consumption due to temporal resolution [9]. However, residential PV battery systems have not been the focus yet.

This paper shall quantify the potential for improving the analysis of expected profitability of residential PV battery systems by using measured load profiles of high temporal resolution. Therefore, we simulate the operation behavior of PV battery systems for 30 households and different temporal resolutions. We compare the results for the expected battery lifetime and resulting net present values (NPV). We then compare the outcome with simulations using two commonly used standard load profiles for German households.

This contribution is structured as follows. After describing the methodology approach in chapter II, the presentation of input data is followed by a discussion of autarky and ownconsumption rates, expected battery life, and an NPV analysis for each household and temporal resolution in chapter III. The computational findings are concluded in chapter IV.

\section{SimUlation APPROACH}

The results are obtained by simulating the operation pattern of PV battery systems for 30 households that are

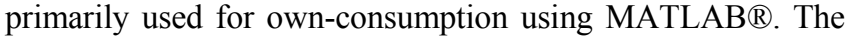
households' electricity consumption was measured over a period of one week in winter and one week in summer. For comparability purposes, we select data from one summer and one winter week from the two SLPs and scale them according to the weekly electricity consumption of the 30 households. In order to account for the high volatility of PV generation, four weeks of PV generation data is used, corresponding to two weeks of winter and two weeks of summer. The data for a whole year is then synthetized both for load and PV generation profiles by copying the measured weeks in a way that the yearly profiles consist of 32 weeks of winter and 20 weeks of summer. The ratio of winter to summer weeks is chosen based on to the type days of the German climate zone no. $13[10]$. Transition days are allocated to winter and summer according to the relative share of these seasons.

In order to run simulations for the temporal resolutions 1 second, 1, 5, and 15 minutes, as well as 1 hour, we generate both load and PV generation profiles at lower temporal resolutions by averaging the measured 1-second profiles. Depending on the yearly household's electricity consumption, one PV battery system is modeled for each household. Based 
on the simulations of the operation pattern for different time resolutions and different households, key parameters such as energy throughput and own-consumption rate are used to forecast battery lifetime and to determine the cost saving potential of the system through an NPV analysis.

\section{Simulation Results}

After describing the data used in the simulations, the results for self-consumption and self-sufficiency rates, battery energy throughput and expected battery lifetime, as well as NPV are presented.

\section{A. Data}

The load profiles used in our analysis were generated in the Austrian research project "ADRES - CONCEPT" [11]. The electricity consumption of 30 households was measured over a period of one week in summer and winter, respectively. The extrapolated households' annual electricity demands range between 2 and $16 \mathrm{MWh}, 30 \%$ of the households consume 5-6 MWh per year. PV power generation data is obtained from a $36.5 \mathrm{~kW}$ ground-mounted PV system which is located at KIT. In order to account for different weather conditions, data from 14 days of summer and 14 days of winter is used. Days with good data quality are chosen between June and July 2013, and January to February 2014. The synthetized PV power generation profile corresponds to a yearly electricity output of $1,003 \mathrm{kWh} / \mathrm{kW}_{\mathrm{p}}$.

In a next step, a PV system size and a battery size is selected for each household. According to [7], the PV system is sized to $0.8 \mathrm{~kW} / \mathrm{MWh}$ annual consumption, whereas the usable battery size is scaled to $1.1 \mathrm{kWh} / \mathrm{MWh}$.

A DC-coupled lithium-ion battery system is chosen as energy storage with one way charging and discharging efficiencies of $95 \%$ and a maximum C-rate of 1 . A depth of discharge of $100 \%$ and no capacity degradation are assumed. However, after 3,000 equivalent full cycles the battery needs to be replaced.

In order to apply for the KfW subsidies, the inverter size is limited to $60 \%$ of the PV size. A second scenario which is only limiting the feed-in of PV electricity to $60 \%$, but not the inverter size itself, is analyzed. Moreover, an inverter replacement is required after 10 years of operation.

The assumptions for the NPV analysis are shown in Table 1. The reference year for all installations is 2015. The main purpose of the PV battery system is the achievement of cost saving rather than capital investment. Consequently, capital costs are neglected.

The NPV is calculated based on the system investment $I_{0}$, yearly revenues generated through the feed in tariff $\left(\mathrm{r}_{\mathrm{t}}\right)$, as well as discounted yearly cost for purchased electricity $\left(\mathrm{ec}_{\mathrm{t}}\right)$, operation and maintenance $\left(\mathrm{oc}_{\mathrm{t}}\right)$, and battery and inverter replacement $\left(\mathrm{rc}_{\mathrm{t}}\right)$. The cash flow is discounted by the discount rate $\mathrm{i}$ over a period of 20 years (1).

$$
N P V=-I_{0}+\sum_{t=0}^{19}\left(r_{t}-e c_{t}-o c_{t}-r c_{t}\right) \cdot(1+i)^{-t}
$$

Table 1. Assumptions for profitability analysis

\begin{tabular}{|l|l|}
\hline Electricity price 2015 & $0.30 € / \mathrm{kWh}$ \\
\hline Rate of electricity price increase & $2 \%$ per year \\
\hline Feed in tariff (January 2015) & $0.1256 € / \mathrm{kWh}$ \\
\hline PV system price (including inverter) & $1,500 € / \mathrm{kW}$ \\
\hline $\begin{array}{l}\text { Subsidized battery system price } 2015 \text { (if } \\
\text { installed with PV system) }\end{array}$ & $700 € / \mathrm{kWh}$ \\
\hline Cost for inverter replacement 2025 & $200 € / \mathrm{kW}$ \\
\hline Cost for battery replacement & $500 € / \mathrm{kWh}$ \\
\hline $\begin{array}{l}\text { Yearly maintenance cost of the PV } \\
\text { battery system }\end{array}$ & $100 €$ \\
\hline Discount rate & $2 \%$ per year \\
\hline
\end{tabular}

\section{B. Implications of using low resolution time series}

In residential PV battery systems, there are two effects that cause fluctuations in the battery operation pattern. One reason is the intermittent nature of PV power generation, another reason is the characteristic gradients of households' load profiles. Battery discharge peaks can occur when a household load peak cannot be covered by the PV system, while charge peaks can be observed when PV generation exceeds the demand. When both effects occur within a short time, a compensation of battery charging and discharging periods can be observed if low resolution load and PV generation profiles are used (Figure 1). A potential impact could be the underestimation of the real battery energy throughput and thus underestimation of the real cycle life and battery ageing. A commonly used indicator that will help us quantifying this effect is the yearly battery full cycle equivalent (FCE), which is the energy throughput divided by the battery capacity. The results are presented in section C. A second effect could be a resulting too low prognosis of the expected additional value of
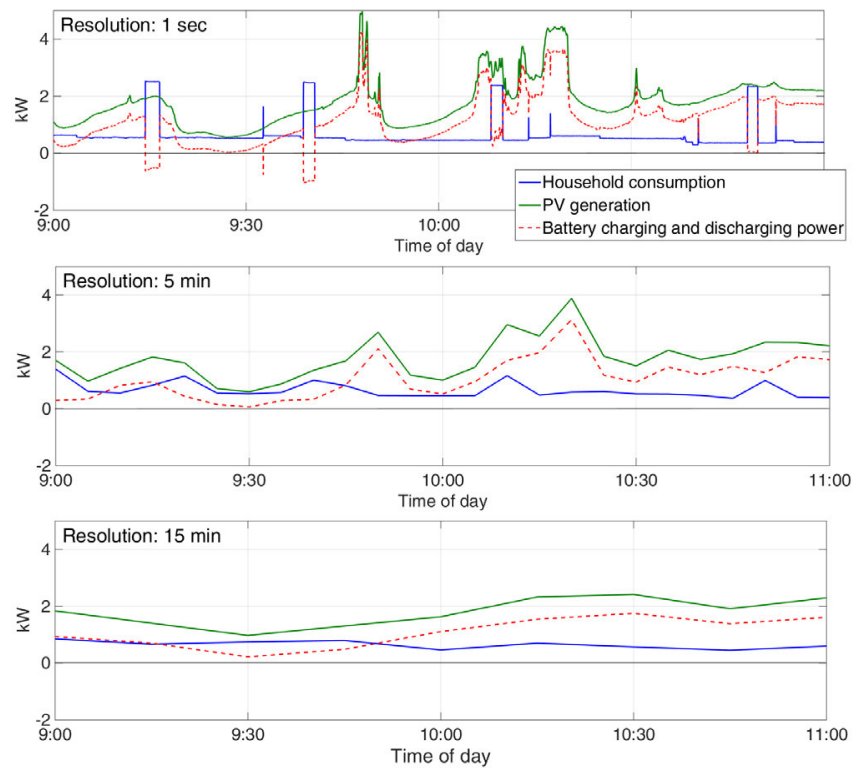

Figure 1. Compensation of charging and discharging periods 
the battery. This is assessed in section D by evaluation selfsufficiency and self-consumption rates. Section E addresses the question of uncertainties related to using SLPs.

\section{Battery energy throughput and expected lifetime}

The FCE at 1 second resolution ranges between 203 for household no. 24 and 267 FCE for household no. 4. The battery of household no. 24 with a yearly electricity consumption of $16 \mathrm{MWh}$ shows the lowest yearly FCE, because the consumption in winter is approximately 4 times higher than in summer, leading to an oversizing of the battery for the summer season. Household no. 4 with a yearly electricity consumption of 5.8 MWh shows a similar pattern for both seasons and a substantial consumption for all days of the week throughout the day.

The yearly energy throughput and thus FCE differ for different temporal resolutions. It can be observed that the average expected yearly FCE decreases from 248 at 1 second resolution by $11 \%$ to 221 at 1 hour temporal resolution (cf. Table 2). The underestimation of yearly FCE ranges between $5 \%$ (household no. 30) and 19\% (household no. 19) for the 1 hour resolution profiles. When only limiting the feed-in of PV electricity, the results are similar.

Table 2. Average underestimation of FCE compared to $1 \mathrm{sec}$ resolution

\begin{tabular}{|l|c|c|c|c|}
\hline Temporal resolution & $1 \mathrm{~min}$ & $5 \mathrm{~min}$ & $15 \mathrm{~min}$ & $1 \mathrm{~h}$ \\
\hline Min. FCE decrease & $0.01 \%$ & $0.89 \%$ & $2.57 \%$ & $4.79 \%$ \\
\hline $\begin{array}{l}\text { Average FCE } \\
\text { decrease }\end{array}$ & $1.52 \%$ & $3.31 \%$ & $5.68 \%$ & $10.70 \%$ \\
\hline Max. FCE decrease & $4.20 \%$ & $6.71 \%$ & $11.52 \%$ & $19.35 \%$ \\
\hline
\end{tabular}

Based on the FCE, we estimate the forecasted battery lifetime, assuming cycle life will be the determining factor. Battery lifetime ranges between 11.2 (household no. 4) and 14.8 years (household no. 24). The underestimation of FCE leads to an average overestimation of battery life between 0.2 and 1.5 years (cf. Table 3 ). This effect is slightly higher for the large inverter, with 1.7 years at 1 hour resolution.

Table 3. Average overestimation of battery life in years

\begin{tabular}{|l|c|c|c|c|}
\hline Temporal resolution & $1 \mathrm{~min}$ & $5 \mathrm{~min}$ & $15 \mathrm{~min}$ & $1 \mathrm{~h}$ \\
\hline $\begin{array}{l}\text { Average increase of } \\
\text { battery lifetime }\end{array}$ & 0.2 & 0.4 & 0.7 & 1.5 \\
\hline
\end{tabular}

However, this effect seems to depend strongly on the household load profile (cf. Figure 2). Pulsing load curves can be observed for the households no. 19 and 24, resulting in a fluctuating battery charging state that is only visible at high temporal resolutions. For four households, a 1 hour temporal resolution leads to an overestimation of the battery's lifetime of only 7-9 months, whereas battery lifetime is overestimated by 3.2 (3.8) years for household no. 24 for the $60 \%$ inverter case (large inverter case). At 15 minutes resolution, the battery lifetime could be overestimated by up to 1.5 years (1.7).

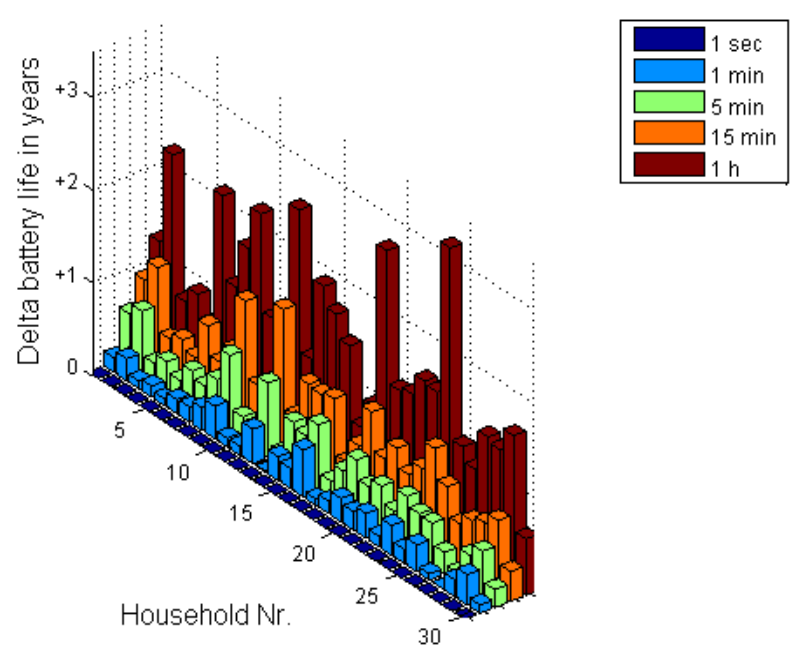

Figure 2. Overestimation of battery's lifetime in years

\section{Self-consumption and self-sufficiency rates}

Electricity that is generated by the PV system and simultaneously consumed by the household is referred to as direct self-consumption. When load is supplied through discharging the battery, which previously has been charged with PV electricity, it is referred to as indirect selfconsumption. The self-consumption rate is then both the direct and the indirect self or own-consumed PV electricity divided by the total generated PV electricity. A high self-consumption rate is desirable when the levelized cost of electricity (LCOE) that consists of a cost share for the PV and the battery falls below grid electricity price ("grid parity").

Self-sufficiency, on the other hand, sets self-consumed PV electricity into relation with the total household electricity consumption. Both self-consumption and self-sufficiency rate increase when adding a battery to the PV system. However, in Germany, high rates of self-sufficiency can usually not be realized in an economical way, especially due to the seasons with low solar irradiation.

Figure 3 shows the effect of temporal resolution on selfsufficiency and self-consumption rates for an exemplary household. Although temporal resolution does not seem to have a major impact on the overall rate, the indirect battery's contribution both to self-sufficiency and self-consumption rates seems to be underestimated at low temporal resolutions, whereas the PV share tends to be overestimated due to the smoothing effect in low resolution time series. As a consequence, the battery's contribution to self-sufficiency and profitability tends to be underestimated.

The average underestimation of the battery's contribution or the overestimation of PV's contribution to both selfsufficiency and self-consumption is shown in

Table 4. The operation pattern with a larger inverter leads to an increase of these figures in the range of $0.1 \%$. 


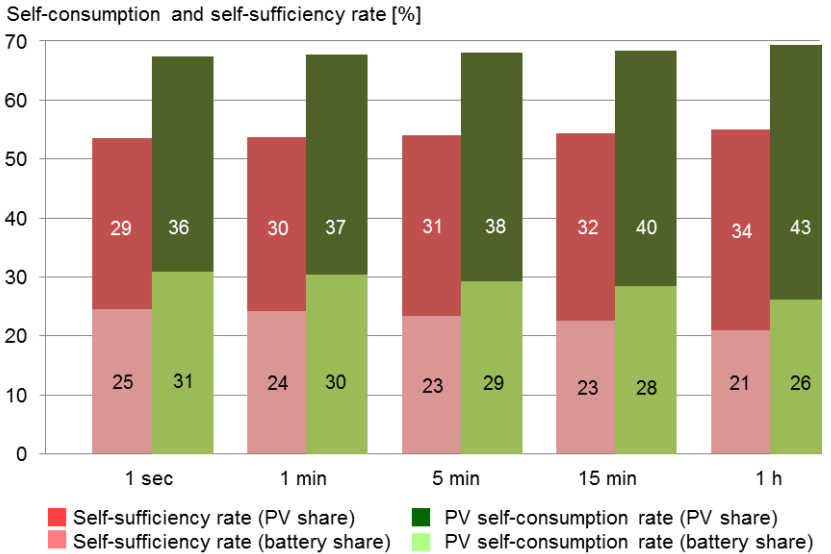

Figure 3. Self-sufficiency and self-consumption rates for household no. 2

Table 4. Average underestimation of battery's contribution in \% points

\begin{tabular}{|l|c|c|c|c|}
\hline Temporal resolution & $1 \mathrm{~min}$ & $5 \mathrm{~min}$ & $15 \mathrm{~min}$ & $1 \mathrm{~h}$ \\
\hline $\begin{array}{l}\text { Decrease of indirect } \\
\text { self-sufficiency rate }\end{array}$ & $1 \%$ & $2.2 \%$ & $3.7 \%$ & $6.8 \%$ \\
\hline
\end{tabular}

\section{E. Uncertainty related to using SLPS}

In a next step, we compare the results with simulations using the SLPs "H0" and "VDI 4655" for German households. These SLPs are most commonly used when no measured data is available. The H0 SLP is available in 15 minutes resolution and shall approximate the cumulative residential load curve. The VDI 4655 SLP is available in 1 minute resolution and is intended as a baseline for calculations of the efficiencies of CHP systems. The SLPs are scaled for each household according to its electricity consumption.

While the averaging of 1 second to 15 minutes time series results in an average underestimation of FCE of $6 \%$, the use of the $\mathrm{H0}$ load profile results in an average underestimation of $14 \%$ (Figure 4). Battery lifetime is thus overestimated by an average 1.7 years, which is slightly higher than the error by using a measured load profile of $1 \mathrm{~h}$ temporal resolution. Only for one household the use of the HO SLP results in a more pessimistic prognosis of battery lifetime. The application of the H0 load profile to household no. 24 with a recurring load of approximately $5 \mathrm{~kW}$ during winter leads to the highest overestimation of battery's lifetime by 4.7 years.

Only the use of the VDI 4655 SLP with higher consumption before sunrise and lower consumption during the day leads to an overestimation of indirect self-consumption and thus to an overestimation of yearly FCE by an average $5.6 \%$, compared to an underestimation by $0.3 \%$ that occurs due to averaging the measured load profiles to 1 minute time series. Consequently, battery's lifetime is slightly underestimated by an average 0.6 years (Figure 4 ).

Comparing self-sufficiency and self-consumption rates of the 15 minutes measures load profiles with the H0 SLP, the overall self-consumption and self-sufficiency rates are overestimated by 3-4\%-points. Compared to the measured 1minute time series, the use of the VDI 4655 SLP results in an overrating of self-sufficiency by $9 \%$, and an underestimation of the self-consumption rate by $6 \%$, especially due to an underestimation of the direct self-consumption.
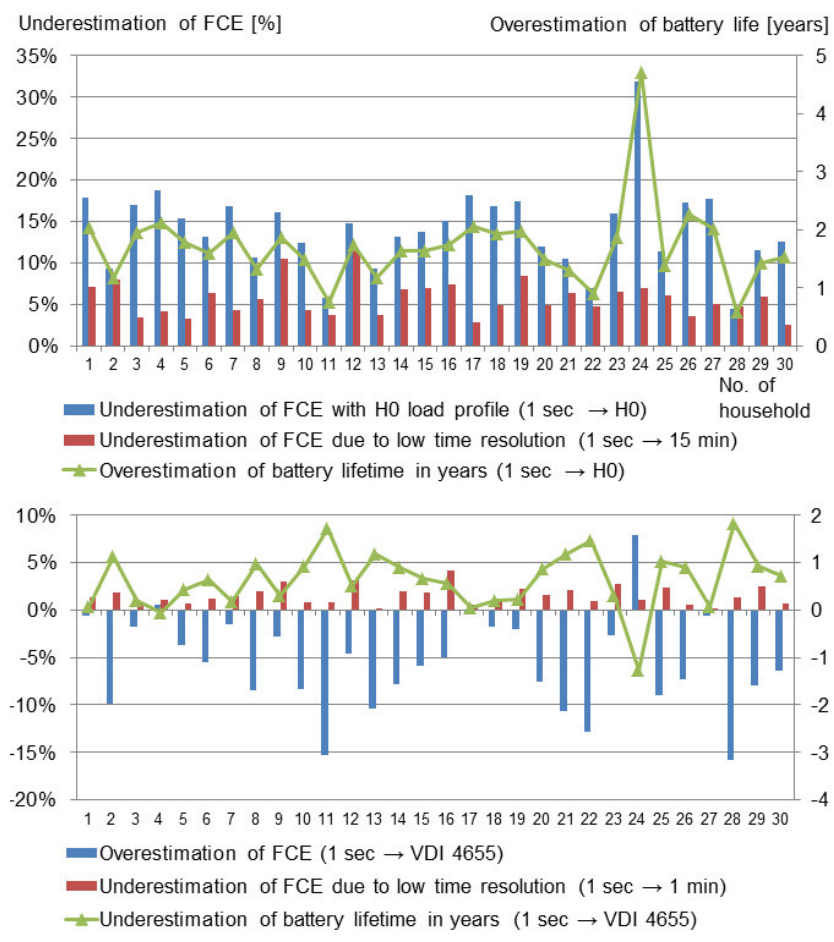

Figure 4. Comparison with the SLPs H0 (top) and VDI 4655 (bottom)

\section{F. Profitability}

Due to the overestimation of battery's lifetime, the cost saving potential might be overrated in low temporal resolution profiles. While the maximum error is $3.9 \%(2.5 \%)$ at 15 minutes resolution and $7.8 \%(4.3 \%)$ at 1 hour resolution in case the inverter is limited to $60 \%$ of the PV size (or limited to $100 \%$ ), the average errors in the NPVs always remain below $3 \%$ (Figure 5).
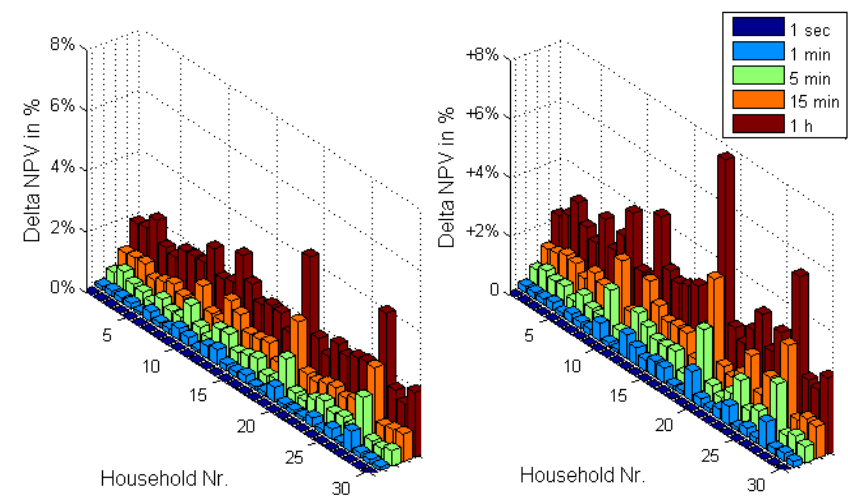

Figure 5. Overestimation of NPV (left: without, right: with inverter limit)

The results indicate an overrating of cost saving potential by using low resolution time series. The overestimation of NPV is even higher when using H0 SLP: the cost saving potential is overrated by $0.6-10.1 \%$ (Table 5). Due to a generally lower self-consumption rate using VDI 4655 SLP, the cost saving potential is rather predicted too pessimistically 
by up to $4.5 \%$. However, for one household the NPV is too optimistic by $3.2 \%$.

Table 5. Average overestimation of cost saving potential in $\%$

\begin{tabular}{|l|c|c|c|c|}
\hline Temporal resolution & $1 \mathrm{~min}$ & $5 \mathrm{~min}$ & $15 \mathrm{~min}$ & $1 \mathrm{~h}$ \\
\hline $\begin{array}{l}\text { Inverter size is } 60 \% \\
\text { of PV size }\end{array}$ & $0.3 \%$ & $0.8 \%$ & $1.4 \%$ & $2.8 \%$ \\
\hline $\begin{array}{l}\text { Inverter size is } \\
100 \% \text { of PV size }\end{array}$ & $0.2 \%$ & $0.6 \%$ & $1.1 \%$ & $2.0 \%$ \\
\hline H0 SLP & - & - & $3.8 \%$ & - \\
\hline VDI 4655 SLP & $-1.1 \%$ & - & - & - \\
\hline
\end{tabular}

\section{CONCLUSION}

This contribution quantifies the uncertainty of using load profiles of low temporal resolution on the expected profitability of residential PV battery systems via a study based on measured load profiles of 30 households.

Two effects can be observed when using time series of low temporal resolution and standard load profiles. One the one hand side, the battery energy throughput tends to be underestimated, showing an average yearly full cycle equivalent of 221 at 1 hour resolution, compared to 248 using 1 second time series. In the worst case, this leads to an overestimation of battery lifetime by 3 to 4 years. The estimated yearly cost saving potential is consequently overestimated by an average 2-3\%. Using 15 minutes temporal resolution, the battery lifetime is overestimated by only 0.7 years, resulting in less severe errors in the NPV calculations around $1 \%$.

The second observation is that the battery's contribution to self-consumption is underestimated. Hence, when analyzing cost saving potentials of a PV battery system based on low resolution time series, a certain share of the added value is attributed to the PV generator, although it should be assigned to the battery system. In further work, this effect could be quantified by LCOE calculations.

The use of standard load profile $\mathrm{H} 0$ in simulations results in a higher error than the use of measured load profiles of 1 hour temporal resolution. In our study, the cost saving potential errors can reach $10 \%$, the results are thus too optimistic. On the other hand, the use of the VDI 4655 standard load profiles generally results in too pessimistic results regarding battery's lifetime and cost saving potential.

A further analysis of the influence of the household behaviour has not been conducted due to the lack of data. A larger variation of the analyzed parameters can be expected if this assessment is conducted for a larger sample and for full year measured load profiles. Moreover, the up-front selected system configuration could have influenced the results.

An alternative to using standard load profiles could be the use of synthetic load profiles generated by bottom-up load models. The uncertainty of temporal resolution on the expected profitability of residential PV battery systems related to the use of bottom-up load models should be analyzed in further work.
Finally, it has to be considered that the profitability of residential PV battery systems might be more sensitive to uncertainties in future electricity price development and battery lifetime than to temporal resolution.

Nevertheless, our findings can be taken into account for choosing an adequate temporal resolution, in case that measurement of real household electricity consumption is planned, or for estimating the error of averaged time series data or standard load profiles. Due to further developments of batteries with regard to prices and cycle life, more detailed results will be particularly valuable for quantifying this development potential.

\section{REFERENCES}

[1] Kreditanstalt für Wiederaufbau (German Reconstruction Credit Institute), "275 Kredit. Erneuerbare Energien - Speicher. Strom aus Sonnenenergie erzeugen und speichern," retrieved from www.kfw.de on $13^{\text {th }}$ May 2014.

[2] Bundesverband Solarwirtschaft (German Solar Industry Association), "Rekordjahr für Solarstrom und Speicher," press release, retrieved from www.solarwirtschaft.de on $8^{\text {th }}$ January 2015.

[3] G. Mulder, D. Six, B. Claessens, T. Broes, N. Omar, J. V. Mierlo, J. V., "The dimensioning of PV-battery systems depending on the incentive and selling price conditions," Applied Energy, vol. 111, pp. 1126-1135, 2013.

[4] T. Kaschub, P. Jochem, W. Fichtner, "Interdependencies of Home Energy Storage between Electric Vehicle and Stationary Battery," in Proceedings of EVS27, Barcelona, Spain, 2013.

[5] J. Li, M. A. Danzer, "Optimal charge control strategies for stationary photovoltaic battery systems," Journal of Power Sources, vol. 258, pp. 365-373, 2014.

[6] E. Waffenschmidt, "Dimensioning of Decentralized Photovoltaic Storages with Limited Feed-in Power and their Impact on the Distribution Grid," Energy Procedia, vol. 46, pp. 88-97, 2014.

[7] J. Weniger, T. Tjaden, V. Quaschning, "Sizing of Residential PV Battery Systems," Energy Procedia, vol. 46, pp. 78-87, 2014.

[8] A. A. Bayod-Rújula, M. E. Haro-Larrodé, A. Martínez-Gracia, "Sizing criteria of hybrid photovoltaic-wind systems with battery storage and self-consumption considering interaction with the grid," Solar Energy, vol. 98 , pp. 582-591, 2013.

[9] S. Cao, K. Sirén, "Impact of simulation time-resolution on the matching of PV production and household electric demand," Applied Energy, vol. 128, pp. 192-208.

[10] VDI Reference load profiles of single-family and multi-family houses for the use of CHP systems, VDI guideline 4655, May 2008.

[11] The Data was generated in the research project "ADRES -CONCEPT" (EZ-IF: Development of concepts for ADRES - Autonomous Decentralized Regenerative Energy Systems, project no. 815 674). This project was funded by the Austrian Climate and Energy Fund and performed under the program „Energie der Zukunft”. Retrieved from www.ea.tuwien.ac.at on $2^{\text {nd }}$ April 2014. 